\title{
DOUBLE-LAYER CAPACITY AT A PYROLYTIC GRAPHITE DISK
} ELECTRODE

HENRY H. BAUERa, NICHAEL S. SPRITZERb AND PHILIP J. ELVING

The University of Michigon, Ann Arbor, Michigan (U.S.A)

(Received October roth, 1966; in revised form October 28th, 1.767 )

An understanding of electrochemical reactions is frequently not attainable unless the structure of the electrical double-layer is understood. The nature of the double-layer at solid electrodes has not yet been adequately elucidated, knowledge about it being largely based on analogy with the well-characterized mercury electrodes; the present state of our understanding in this area has been comprehensively reviewed by DELAHAY 1 .

Primary difficulties with solid electrodes involve questions as to: (a) the reproducibility of the electrode surface and (b) the dependence of the apparent double-layer capacity on frequency. The aim of the present study was to investigate these questions in relation to the pyrolytic graphite electrode, which has in recent years proved usefui in a variety of electrochemical studies; particular attention was given to electrode preparation and treatment.

The observed capacity was always to some extent dependent on the frequency at which the measurement was made. However, it is indicated that such an effect may be expected at any electrode, such as a dis!, at which the distribution of current over the surface is not uniform.

EXPERIMENTAI

\section{Polarization circuit}

Instrumentation for polarization by both alternating and direct voltages has been either fully manual, with corrections for $i R$-drop and other effects being calculated after the experiments have been made ${ }^{2}$, or fully controlled with both d.c. and a.c. signals held constant by electronic circuits, usually constructed of operational amplifiers ${ }^{3}$. The latter scheme has the disadvantage that, with readily available equipment, work is restricted to frequencies no higher than about xooc Hz. Therefore, a "hybrid" arrangement (Fig. I) was used in the present work, in which a.c. and d.c. circuits were connected in parallel across the cell.

The d.c. circuit was controlled by a conventional operational-amplifier controlloo $\mathrm{p}^{4}$; the direct voltage was applied by potentiometer, E: capacitor $\mathrm{C}_{2}$ was used to

aPresent address: Department of Chemistry, University of Kentucky, Lexington, Fentucky, U.S.A.

present address: Department of Chemistry, Villanova University, Villanova, Pennsylvania. U.S.A. 
attenuate any a.c. picked up by the reference electrode; choke $L$ ensured that a.c. applied between counter and working electrodes was not shunted through $\mathrm{C}_{2}$ to ground.

The a.c. circuit, supplied by an audio-frequency oscillator, was manually controlled. A parallel combination of resistance $\left(R_{p}\right)$ and capacitance $\left(C_{p}\right)$ decades was used for phase-angle measurement; phase shifts and cell impedances were measured as previously described5, using an oscilloscope. A ro-mV peak-to-peak voltage was maintained across the working electrodes by manual adjustment of $R_{1}$ and of the oscillator am.plitude-control. Capacitor $C_{1}$ blocked the d.c. signal from the a.c. circuit.

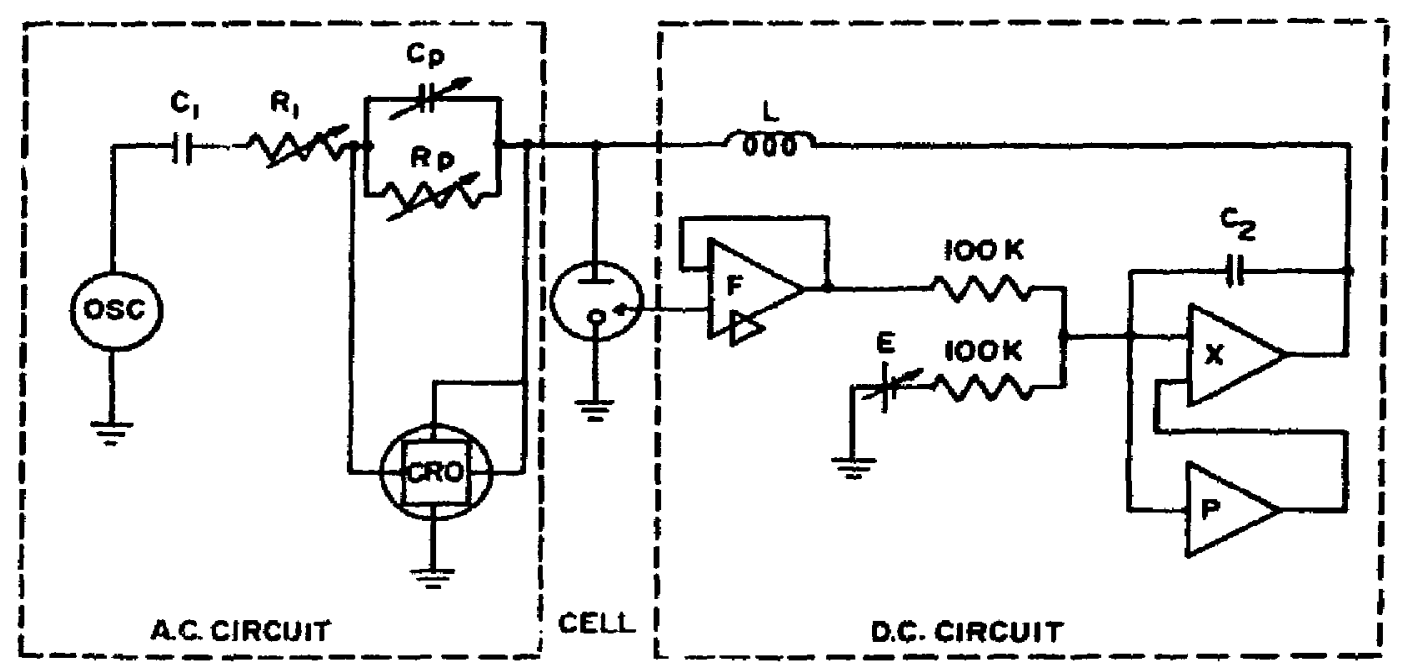

Fig. I. Circuit for a.c. measurements. $\left(C_{1}\right)$, o.oI $\mu \mathrm{F} ;\left(C_{2}\right), 2 \mu F ;\left(C_{p}\right)$, General Radiodecade capacitor Type 14 I9-A ; (CRO), Tektronix Model $502 \mathrm{~A}$ dual-beam oscilloscope; (E), o-Io V variable potential source; (F), stabilized follower; (L). United Transformer choke Type MQM-60o; (OSC). Heathkit audio-frequency oscillator Model AG-8; (P). Philbrick K2-P operational amplifier; ( $\left.R_{1}\right)$, two 3/4turn radio potentiometers in series, $5 \mathrm{k} \Omega$ and $I-M \Omega ;\left(R_{p}\right)$. General Radio decade resistor $T y p e$ I 434-QC; (X), Philbrick K2-X operational amplifier.

\section{Cells}

For runs in aqueous solution, a conventional $\mathrm{H}$-cell was used with a saturated calomel electrode, SCE, as reference electrode, and an agar plug between compartments. The counter electrode, which was placed in the test-solution compartment, consisted of either a large mercury pool (area: $9.6 \mathrm{~cm}^{2}$ ) or a platinum gauze cylinder, I $\mathrm{cm}$ in diameter and $3 \mathrm{~cm}$ high (ca. 26 gauge wire). The three-compartment waterjacketted cell used for runs in pyridine solution has been described ${ }^{6}$; salt bridges were methyl cellulose gel-o.I $M \mathrm{Et}_{4} \mathrm{NClO}_{4}$ in pyridine. Runs in aqueous solution were at ambient room temperature (no significant effect of temperature changes of a few degrees on capacity has been reported); runs in pyridine solution were at $25^{\circ}$.

\section{Graphite electrode}

Pyrolytic graphite electrodes (P.G.E.) made from 4-mm diameter cylinders sealed into glass tubing were prepared as previously described 7 with the graphite surface flush with the end of the glass tubing, as well as with several millimeters of graphite protuding from the tubing; in the latter case, the sides of the graphite cylinder were insulated. Shell Epon resin, Sears two-component epoxy resin, and polyethylene (obtajned by melting polyethylene tubing in a low flame) were tried for sealing and insuiation. Resurfacing was accomplished by polishing with a fine abrasive paper ${ }^{7}$ 
or by cleaving about a millimeter of graphite from the electrode tip by means of a sharp scalpel. The most reproducible behavior was obtained with a "protruding" electrode, sealed and insulated with Sears epoxy resin and resurfaced by cleaving.

\section{Reagents}

Aqueous potassium chloride (J. T. Baker) solutions were purified by treatment with charcoal (Darco G-6o). Pyridine, argon for de-aeration, and tetraetinylammcnium perchlorate were obtained and treated as previously described".8. The argon was equilibrated in the case of aqueous solutions by first being bubbled through water; for pyridine solutions, it was first passed through a column of Drierite and then through pyridine cortaining molecular sieves.

\section{MEASUREMENT APPROACH}

The measuring technique involved determination of total cell impedance, $Z$, and phase angle, $\phi$, and calculation of the equivalent series resistance, $R_{\mathrm{s}}$ and capacity $C_{\mathrm{s}}$ (the apparent double-layer capacity), by simple transformation of the measured quantities. Thus,

$$
Z^{2}=R_{s}^{2}+I / \omega^{2} C_{s}^{2}
$$

where $\omega$ is the angular frequency of the applied alternating signal, and

$$
\cot \phi=\omega R_{5} C_{s}
$$

Combining eqns. (2) and ( 1 ),

$$
Z^{2}=R_{\mathrm{s}}{ }^{2}+R_{\mathrm{s}}^{2} / \cot ^{2} \phi=R_{\mathrm{s}}^{2} / \cos ^{2} \phi
$$

which permits $R$ to be calculated directly from $Z$ and $\phi$ via

$$
R_{\mathrm{s}}=Z \cos \phi
$$

$C$ can then be calculated, using eqn. (2), from

$$
C_{\mathrm{s}}=\mathrm{I} / \omega Z \sin \phi
$$

If $R_{\mathrm{s}}$ and $C_{\mathrm{s}}$ are independent of frequency, support is given to a representation of the cell as being the double-layer capacity at the working (small) electrode in series with the solution resistance, and $C_{\mathrm{s}}$ and $R_{\mathrm{B}}$ can be taken to be measures of these quantities. However, if $R_{s}$ and $C_{B}$ change with frequency ("frequency dispersion"), such inferences cannot be drawn. It is worth emphasizing that, when the equivalent series circuit is inapplicable, use of $C_{\mathrm{s}}$ as a "double-layer capacity" involves an assumption whose validity does not necessarily improve as the frequency dispersion becomes less; it is the applicability or inapplicability that is significant, since any frequency dispersion points to a phenomenon that must be understood before $C_{\mathbf{s}}$-values can be reliably used.

REPRODUCIBILITY AND FREQUENCY DISPERSION

The reproducibility, nature, and magnitude of the frequency dispersion obtained on pyrolytic graphite electrodes (Tables $I$ and 2 ) indicate that good reproducibility may be attained at a given electrode by rigorous control of the preparation and handling of the electrode (cf. subsequent discussion). 
However, both the magnitude of the measured quantities and their variation with frequency are sensitive to the method of preparation of the electrode surface: compare data in Table $I$ for a cleaved electrode and Table $\approx$ for a polished electrode cathodized before the impedance measurements were made. Thus, one possible factor

\section{TABLE 1}

SERIES CAPACITY AND RESISTANCE AT A CLEAVED PYROLYTIC GRAPHITE ELECTRODE*

\begin{tabular}{|c|c|c|c|c|c|c|}
\hline \multirow{2}{*}{$\begin{array}{l}\text { Frequency } \\
(\mathrm{Hz})\end{array}$} & \multicolumn{3}{|c|}{$C^{\circ}(\mu F)$} & \multicolumn{3}{|c|}{$R_{a} \circ(\Omega)$} \\
\hline & $(x)$ & (2) & (3) & $(x)$ & (2) & (3) \\
\hline 50 & 2.09 & $2 \cdot 36$ & $2 \cdot 34$ & 256 & 279 & 285 \\
\hline 125 & I. 85 & 2.13 & 2.14 & 129 & 146 & 143 \\
\hline $\begin{array}{l}250 \\
500\end{array}$ & $\begin{array}{l}1.76 \\
1.61\end{array}$ & $\begin{array}{l}1.96 \\
1.78\end{array}$ & $\begin{array}{l}2.60 \\
1.78\end{array}$ & $\begin{array}{l}81.8 \\
56.6\end{array}$ & $\begin{array}{l}90.5 \\
62\end{array}$ & $\begin{array}{l}96 \\
58.1\end{array}$ \\
\hline 1,250 & 1.53 & I. 54 & I. 80 & 36.7 & 37.6 & 31 \\
\hline 2,500 & I. 43 & 1.42 & 2.05 & 30.8 & 28.5 & 39.4 \\
\hline 5,000 & 1.31 & 1.21 & 1.27 & 26.6 & 23.2 & 22.2 \\
\hline 12,500 & 1.26 & 1.12 & 1.07 & 23.4 & 17.6 & 17.8 \\
\hline 25,000 & 1.20 & 1.03 & 1.83 & 22.4 & 15.8 & 15.8 \\
\hline
\end{tabular}

- Electrode (diam. $4 \mathrm{~mm}$ ) was sealed and covered by a polyethylene pressure-fitted sleeve. Soln. composition : $0.4 \mathrm{M} \mathrm{KCl}$.

Measurements were made at a potential of $-0.5 \mathrm{~V} v s$. SCE. The numbers in parentheses refer to the series of experiments made on the same electrode with resurfacing by cleaving between each series.

\section{TABLE 2}

SERIES CAPACITY AND RESISTANCE AT A GROUND PYROLYTIC GRAPHITE ELECTRODE*

\begin{tabular}{|c|c|c|c|c|}
\hline \multirow{2}{*}{$\begin{array}{l}\text { Frequency } \\
(I: z)\end{array}$} & \multicolumn{2}{|c|}{$C \cdot b(\mu F)$} & \multicolumn{2}{|c|}{$R_{a} \mathrm{~b}(\Omega)$} \\
\hline & $(I)$ & (a) & $(I)$ & (2) \\
\hline 50 & 8.8 & 8.8 & $4^{8.5}$ & 47.8 \\
\hline 125 & 8.42 & 8.25 & 35.2 & $34 \cdot 4$ \\
\hline 250 & 9.05 & 7.85 & 28.8 & $3 I$ \\
\hline 500 & 7.95 & 7.8 & 29 & 28.9 \\
\hline 1,250 & 7.92 & $7 \cdot 25$ & 26.6 & 26.8 \\
\hline 2,500 & 8.9 & 6.95 & 23.9 & 26.5 \\
\hline 5,000 & 6.58 & 6.36 & $24 \cdot 5$ & $24 \cdot 5$ \\
\hline 12,500 & 6.6 & 5.66 & $24 \cdot 5$ & 23.9 \\
\hline 25,000 & 9.65 & & $2 I$ & \\
\hline
\end{tabular}

Electrode (diam. $4 \mathrm{~mm}$ ) was sealed in a glass tube by polyethylene with its end flush with the glass; it was resurfaced by grinding. Soln. composition: $0.5 \mathrm{M} \mathrm{KCl}$.

bMeasurements were made at a potential of $-0.5 \mathrm{~V}$ vs. SCE. In series ( 1 ), the soln. was pre-electrolyzed initially by cyclic scan to - $1.0 \mathrm{~V}$; in series (2). the soln. was similarly pre-electrolyzed before each measurement.

in the differences observed is the presence or absence of an "oxidized" surface. The P.G.E. normally has an "oxidized "surface that shows a different apparent capacity than the "reduced" surface"; the latter can be produced, e.g., by polarizing the electrode from o to $-\mathrm{r} .4 \mathrm{~V}$ vs. SCE at to $\mathrm{mV} \mathrm{sec}-1$. Therefore, if an "oxidized" electrode is held at a negative potential, the capacity would be expected to change with time. We have occasionally observed such effects, where the order of magnitude of the drift is about a $5 \%$ change in capacity in $15 \mathrm{~min}$ while the resistance remains constant or is 
changed to a lesser extent; these changes appear to depend on applied electrode potential and on the frequency. No quantitative data bearing on this particular point were obtained; however, work is continuing on the study of the nature of the surface ("oxidized" or "reduced"), in particular by cyclic voltammetric investigations".

Another possible factor in the small frequency dispersion that was persis'ently observed (e.g., Tables I and 2) may have been penetration of the solution between the electrode and its insulation. For example, in one of a number of experiments that gave a much larger $C_{\mathrm{s}}$-value at low frequencies (a factor of up to 4 over Table 2 ) together with a much greater degree of frequency dispersion (Table 3), the resin coating around

TABLE 3

EFFECT ON SERIES CAPACITY AND RESISTANCE OF SEEPAGE OF SOLUTION BETWEEN PYROLYTIC CRAPHITE EIECTRODE AND ITS INSULATIONG

\begin{tabular}{|c|c|c|c|c|}
\hline \multirow{2}{*}{$\begin{array}{l}\text { Frequency } \\
(H z)\end{array}$} & \multicolumn{2}{|c|}{$C_{s} \nabla(\mu F)$} & \multicolumn{2}{|c|}{$R_{s}{ }^{\prime}(\Omega)$} \\
\hline & (I) & (2) & (I) & (2) \\
\hline 50 & 27.9 & 33.8 & т99 & $r 6_{4}$ \\
\hline 125 & 30.9 & 29.9 & IOI & 103 \\
\hline 250 & 22.9 & $24 \cdot 1$ & 77.2 & $74 \cdot 9$ \\
\hline 500 & 22.5 & 18.2 & 89.3 & 75 \\
\hline$I, 250$ & 4.55 & 4.75 & $53 \cdot 4$ & 52.5 \\
\hline 2,500 & 3.26 & $3 \cdot 3^{8}$ & $37 \cdot 7$ & $37 \cdot 3$ \\
\hline 5,000 & 1.75 & 1.92 & 31.7 & $3 x$ \\
\hline$I 2,500$ & I.70 & 1.70 & 23.8 & 23.8 \\
\hline 25,000 & 1.69 & I. 60 & $2 \mathrm{I} \cdot \bar{T}$ & $2 I .1$ \\
\hline
\end{tabular}

Electrode was encased in a two-component epoxy resin and was resurfaced by cleaving. Soln. composition: $0.4 M \mathrm{KCl}$.

bMeasurements were made at a potential of $-0.5 \mathrm{~V}$ vs. SCE. In series (I), a pool counter-electrode was used; in series (2), a platinum gauze cylinder counter electrode was used; the lack of any difference in the two series indicate that both counter-electrodes were equally effective.

the electrode became opaque and readily peeled away, evidently due to penetration of solution between electrode and resin. Continuous penetration is not necessarily involved, but merely the presence of a "wedge" of solution. The latter has been identified as a cause of frequency dispersion under some circumstances ${ }^{10-14}$; in fact, such an explanation is commonly invoked in a qualitative way to explain frequency dispersion, but quantitative support for the explanation is not usually available. At solid electrodes, roughness of the surface is another explanation commonly given for the observation of frequency dispersion.

Both explanations amount to the use of an equivalent circuit in which the lines of current flow have to be represented by a number of parallel paths, each with capacitive and resistive properties, whereas a lack of frequency dispersion permits the use of an equivalent circuit consisting of only one path for current flow, viz. through the capacity of the interface and the ohmic resistance of the solution in series. Thus, any physical situation in which the current density is not uniform over the surface of the electrode will result in frequency dispersion. In the following section, we discuss the possibility that such an effect is inherently present when a disk-shaped indicator electrode is used. 
Statements in the literature refer to the need for a symmetrical arrangement of electrodes if frequency dispersion is to be avoided, for example, in the work of Grahame:

“...Hanging droplet... not significantly different from d.m.e... with (large cupped $\mathrm{Hg}$ surfaces) ... frequency effect always exceeded that ... with droplets, and its magnitude depended critically upon the size and shape..." (p. 305 of ref. 10; $c f$. also column I of p. 307).

"...Generally... dispersion is greater on wires and sheets than on spheres... more difficult to satisfy the symmetry requirements..." (almost at end of ref. 15).

"... The necessity for smoothness and spherical symmetry (or any other symmetry which assure an equal flow of current to all points of the electrode surface)... Robertson ... points out the enormous increase in the apparent series resistance... with platinum electrodes as the frequency is lowered... also noted by the writer... not only with platinum but also with other types of solid electrodes and to a lesser degree even with mercury. The effect with mercury has been ... apparently explained ... as being due to the creeping of the solution up the inner walls of the capillary... It is not clear that any similar explanation will suffice to explain the results observed with solid microelectrodes. The (series) capacity of a spherically symmetrical smooth solid electrode is virtually unaffected by the frequency... This fact can be used as a test for smoothness and symmetrv of an electrode." (p. 353 of ref. I6).

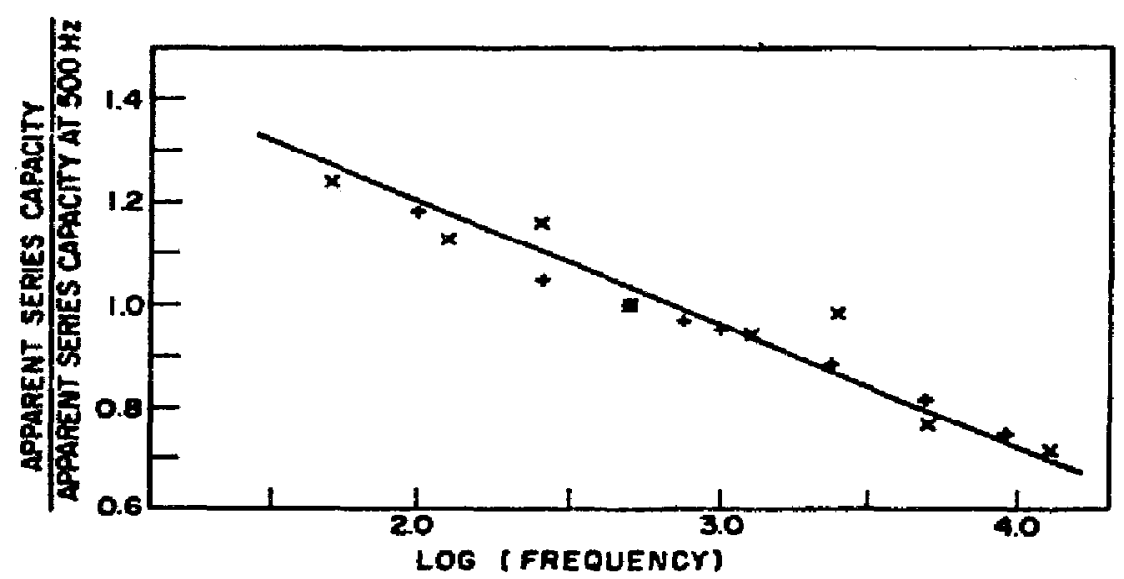

Fig. 2. Frequency dispersion of apparent double-layer capacity at planar disk-shaped working electrodes. $(x)$, results obtained in the present study, taken from Tables $I$ and $2 ;(+)$, results reported by GRANTHAM ${ }^{18}$ at mercury. The line was calculated by assuming that all results follow the same relation.

In connection with our work, the question now arises whether a symmetrical arrangement of electrodes was achieved. We were not able to detect differences between the results obtained with a large mercury pool as counter electrode as compared with a large cylindrical platinum gauze counter electrode. Such a test is inconclusive, however, since the important feature is the current distribution at the diskshaped working electrode, which could be very similar with the two counter-electrodes used. In point of fact, in a theoretical discussion of the distribution of direct current in electrodeposition, it has been shown that there are only three arrangements of electrodes in which it is possible to obtain an absolutely uniform current dis- 
tribution over the electrodes: concentric spheres, concentric cylinders, and infinite parallel planes 17 . Thus, it seems that frequency dispersion will be inherently connected with the use of disk-shaped working electrodes.

Some support for this expectation may be found in data obtained at a plane mercury disk electrode1", where dispersion of the observed capacity with frequency was observed. Moreover, the magnitude of this dispersion is comparable to that found in the present work (cf. Fig. 2).

Given that a variation of measured capacity with frequency is the result of non-uniform distribution of current, an equivalent circuit would then be composed of a set of capacities and resistors, $C_{3}$ and $R_{1}$, arranged so that there are parallel paths, each of which contains one $C$ and the corresponding $R$. It is readily seen that in such an arrangement, extrapolation to sufficiently low frequencies will yield the sum of the individual capacities $C_{1}$; sufficiently low frequencies require that all of the $R_{1}$-values will be small compared with the corresponding ( $\left(2 / 2 \pi f C_{1}\right)$ terms. The results in Table 2 may have approached this requirement; however, as mentioned, unresolved questions on the nature of the surface preclude further discussion at this stage of the significance of the numerical values obtained in these measurements.

\section{EFFECT OF ELECTRODE POTENTIAL ON DOUBLE-LAYER CAPACITY}

In studies where frequency dispersion is absent or ignored, measurements of the double-layer capacity are commonly made with signals of $1000 \mathrm{~Hz}$ or thereabouts. At solid electrodes ${ }^{19}$, the measured capacities generally are similar to those at mercury in that the capacity rises at both positive and negative polarizations and shows a more

\section{TABLE 4}

SERIES RESISTANCE AND CAPACITANCF AT A PYROLYTIC GRAPHITE ELECTRODE OF A PYRIDINE SULUTION OF TETRAETHYLAMMONILM PERCHLORATE (O.I M) AT $250 \mathrm{~Hz}$

\begin{tabular}{lll}
\hline $\begin{array}{l}\text { Potentiale } \\
(V)\end{array}$ & $\begin{array}{l}R_{0}^{\mathrm{b}} \\
(\Omega)\end{array}$ & $\begin{array}{l}C . \mathrm{b} \\
(\mu F)\end{array}$ \\
\hline 1.0 & 286 & 16.5 \\
0.7 & 287 & 14.5 \\
0.5 & 290 & 13.5 \\
0.3 & 294 & 11.9 \\
0.2 & 296 & 11.4 \\
0.1 & 299 & 9.8 \\
0 & 300 & 10.0 \\
-0.1 & 302 & 11.2 \\
-0.2 & 301 & 12.4 \\
-0.3 & 294 & 11.7 \\
-0.5 & 290 & 13.4 \\
-0.7 & 289 & 15.0 \\
-1.0 & 284 & 17.0
\end{tabular}

- Is. N.Ag.E.: Ag/I M AgNOz in pyridine 27. -The values are averages of from one to five ceparate experiments, normalized for 1o $\mu F$ and $300 \Omega$ at $o \mathrm{~V}$ : the actual capacity at o $V$ was about $60 \mu \mathrm{F} / \mathrm{cm}^{2}$ of macroscopically measured surface.

\section{TABLE 5}

EFFECT OF APPLIED POTENTIAL ON SERIES CAPACITY AND RESISTANCE AT A PYROLYTIC GRAPHITE ELECTRODE

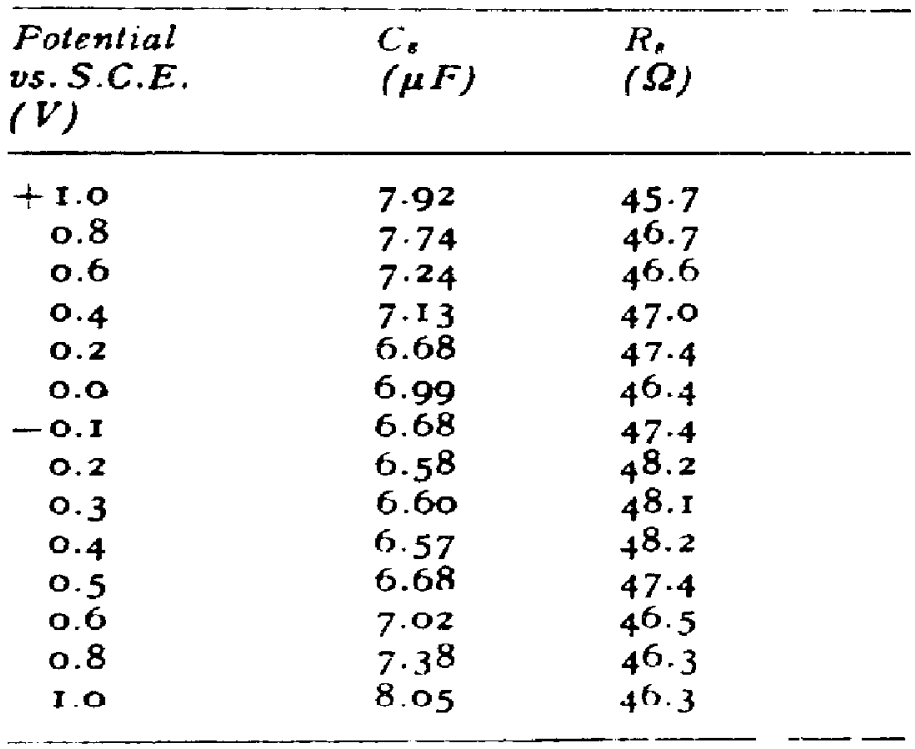

- Electrode (diam. $4 \mathrm{~mm}$ ) was sealed i.l a glass tube by polyethylene with its end 'lush with the glass; it was resurfaced by polishing. Soln. composition: $0.5 M \mathrm{KCl}$. Frequency: I $000 \mathrm{~Hz}$. 
or less pronounced minimum at intermediate potentials; the minimunı capacity is sometimes taken as a measure of the potential of zero charge. In order to compare the behavior of the P.G.E. with that of other solid electrodes in this respect, measurements were made at a fixed frequency with changing electrode potential (Tables 4 and 5 ).

In aqueous $\mathrm{KCl}$, the capacity appeared to show a very shallow minimum between ca. - 0.2 and $-0.4 \mathrm{~V}$ ws. $\mathrm{SCE}$; in $0.1 M \mathrm{Et}_{4} \mathrm{NClO}_{4}$ in pyridine, a distinctminimum in the capacity lay close to o V vs. N.Ag.E.20 In the latter system, polarization beyond - I.o V produced an ineversible change in the electrode surface, i.e., results obtained after such a polarization and a return to less negative potentials were scattered and unreproducible. In aqueous $\mathrm{FCCl}$ solution, such behavior results from reduction of an "oxidized" surface ( $c f$. previous discussion) or from the formation of hydrogen through discharge of prctons ${ }^{21}$; the reactions, which may occur in pyridine to alter the graphite surface, have not yet been elucidated.

\section{ACKNOWLEDGEMENTS}

The authors thank the U.S. Atomic Energy Commission and the Horace H. Rackham School of Graduate Studies and the Institute of Science and Technology of The University of Michigan, which helped support the work described. They are indebted to Dr. WILBUR SHULTS for drawing their attention to the work of KASPER.

\section{SUMMARY}

The apparent double-layer capacity at pyrolytic graphite electrodes has been measured over a wide range of frequencies $(50-25,000 \mathrm{~Hz})$ in aqueous and in pyridine solutions. The capacity varied with frequency, as did the series resistance; various methods of preparation of the electrode surface were tried, but with no indication that the frequency-dependence could be eliminated along this line of approach to the problem.

It is suggested that the frequency dispersion may be at least in part an effect of electrode geometry since the distribution of current at a disk electrode is not uniform across the surface.

\section{REFERENCES}

I P. Defahay, Double Layar and Electrode Kinetics, Interscience Publishers, New York, I965.

2 B. Brever ano H. H. BAuER. Alternating Curyent Polarography and Tensammetry, Interscience Publishers, New York, 1963 , chap. 3 .

3 D. E. SMIrн, Asal. Chem., 35 (I9б人) I 8 I I.

4 W. I. UNDERKOFIER AND I. SHAIN, Anal. Chem., 35 (I963) 1778.

5 H. H. Bauler and P. J. Elving, J. Am. Chem. Soc., 82 (I960) 209 r.

6 M. S. SpRITZER AND P. J. ElviNg, work in progress.

7 W. R. TURNFR AND P. J. Elvisg, Anal. Chem., 37 (1965) 207-

8 ir. S. Spritzer, J-M. Costa AND P. J- ElviNg, -Anal. Chem., 37 (I965) 2 II.

9 M. ROSEN, H. H. DAUER AND P. J. ẼVING, work in progress.

xo D.C. Graflane, $J$. Am. Chem. Soc. 63 (I946) 30 .

I V. I. MELIK-GaIKazyan, Zh. Fiz. Khim., 26 (I962) 560 (translated by D. C. GRAFAME).

2 K. Rosenthal and B. Ershler, $Z h$. Fiz. Khim., 22 (194S) r 344 (translated by R. Parsons).

r E. A. Unshe, N. G. Bufun Axd D. I. Leikis, Russ. $J$. Phys. Chem. English Transl., 36 (Ig6z) :260.

I4 D. I. Leikis, E. S. Sevastyanov and I. L. Kriots, Russ. $J$. Phys. Cheme. English Transl., 38 (1964) 997 .

J. Electroanal. Chem., $x_{7}$ (1968) 299-307 
I5 D.C. GRafaMe, $J$. Electrochem. Soc., 99 (I952) $370 \mathrm{C}$.

I 6 D.C. Grahame, Anre. Rev. Phys. Chem., 6 (I955) 337.

I7 C. FASPER, Trans. Electrochem. Soc., 77 (I940) 353.

I8 D. H. Gravtiam, Ph. D. Thesis, Iovia State Univ., 1963; Univ. Microfilms, Order No. 63-2973

I9 A. N. Frumkin AND B. B. Damaskix, Modern Aspects of Electrochemistry No. 3 , edited by J. O'M. Bockris and B. E. Cowway, Butterworths, Washington, 1964, pp. 149-223.

20 A. Cisak AND P. J. ElviNG, $J$. Electrochem. Suc., i Io (1963) igo.

2 I M. Rosen AND P. J - Elving, work in progress.

J. Electroanai. Chem., I7 (I968) 299-307 